\title{
FOETOMATERNAL OUTCOME IN ECLAMPSIA IN TERTIARY CARE HOSPITAL
}

\author{
Arti Tuli' ${ }^{1}$ Juhi Rathi2, Neha Garg 3 , Ruchi Vashisht ${ }^{4}$
}

${ }_{1}^{1}$ Associate Professor, Department of Obstetrics and Gynaecology, Christian Medical College and Hospital, Ludhiana, Punjab, India. 2Ex-Resident, Department of Obstetrics and Gynaecology, Christian Medical College and Hospital, Ludhiana, Punjab, India. 32nd Year Resident, Department of Obstetrics and Gynaecology, Christian Medical College and Hospital, Ludhiana, Punjab, India. ${ }_{4}^{4}$ st Year Resident, Department of Obstetrics and Gynaecology, Christian Medical College and Hospital, Ludhiana, Punjab, India.

\section{ABSTRACT}

\section{BACKGROUND}

Eclampsia is defined as preeclampsia with convulsions that cannot be attributed to another cause. Eclampsia continues to be a major cause of maternal morbidity and mortality.

\section{MATERIALS AND METHODS}

It was a retrospective descriptive study conducted in Christian Medical College and Hospital, Ludhiana over a period of 5 years. During this period, 70 patients of eclampsia were studied and the incidence of eclampsia, socio-demographic parameters, clinical presentation, type of eclampsia, mode of delivery and its foetomaternal outcome were noted.

\section{RESULTS}

Incidence in our study was 1.01\%. This study showed that eclampsia was seen between 19 - 24 years of age group, in primigravida, unbooked and illiterate patients. Antepartum eclampsia was seen in $46(60 \%)$ patients. Vaginal delivery occurred in 36 patients and 34 patients had LSCS. Most common complications were HELLP syndrome, pulmonary oedema and acute renal failure. Overall, 4 maternal deaths were reported. Neonatal outcome included live births in 57 (81.42\%), fresh still births in 8 (11.42\%) and 5 (7.14\%) already had intrauterine deaths. Foetal complications like severe birth asphyxia, respiratory failure, hyaline membrane disease and meconium aspiration syndrome were seen.

\section{CONCLUSION}

Eclampsia remains a major cause of maternal mortality in India, resulting from unplanned pregnancies and unsupervised deliveries. To defeat this powerful enemy, and decrease the burden of maternal deaths, we need to educate and encourage the general public to opt for prompt antenatal, intranatal and postnatal care.

\section{KEY WORDS}

Eclampsia, Maternal Mortality, Perinatal Morbidity.

HOW TO CITE THIS ARTICLE: Tuli A, Rathi J, Garg N, et al. Foetomaternal outcome in eclampsia in tertiary care hospital. J. Evolution Med. Dent. Sci. 2018;7(41):4420-4423, DOI: 10.14260/jemds/2018/987

\section{BACKGROUND}

Eclampsia is defined as preeclampsia with convulsions that cannot be attributed to another cause. ${ }^{1}$ It is a life-threatening emergency. The condition affects between 1 in 30 and 1 in 500 pregnancies in India. ${ }^{2}$ Eclampsia is the third commonest causes of maternal mortality after haemorrhage and infection in the developing countries. ${ }^{3}$ Every year more than 50000 maternal deaths occur due to eclampsia in developing countries.4,5 Maternal mortality is an important indicator of health care system of a society. While India has failed to achieve MDG goal, since MMR in 2015 was found to be 174 . To achieve MDG 5 (on maternal health), India needed to reduce MMR from 437 deaths per 100,000 live births in 1991 to 100 by 2015 . Almost 150 women are dying in India as per 2010. This means 1 woman is dying every 10 minutes. At the same time India has recorded 38\% decline in maternal deaths between 1999 and 2009.6,7

'Financial or Other Competing Interest': None.

Submission 30-08-2018, Peer Review 23-09-2018,

Acceptance 29-09-2018, Published 08-10-2018.

Corresponding Author:

Dr. Arti Tuli,

Associate Professor,

Department of Obstetrics and Gynaecology,

Christian Medical College and Hospital,

Ludhiana-141008, Punjab, India.

E-mail: tuliarti@yahoo.co.in

DOI: $10.14260 /$ jemds $/ 2018 / 987$
There has been progress, but we are not there yet. The major cause of maternal mortality in eclampsia is increased risk of abruption, DIC, ARF and cerebral haemorrhage. In developed countries with effective antenatal screening programs, advanced diagnostic and therapeutic interventions, the disease has become a rare complication of pregnancy and maternal mortality rate is reduced to $1 \%$ in women with eclampsia. While in developing countries, due to lack of early antenatal booking, irregular antenatal check-ups, low socio-economic status, poor health education and delayed referral to higher centre the incidence of eclampsia still remains alarmingly high. The present study was undertaken to study the foetomaternal outcome in eclampsia, so as to highlight the need for early antenatal booking, regular antenatal check-up and timely referral to curb this preventable problem.

\section{Aims and Objectives}

To study the incidence of eclampsia, socio-demographic parameters, clinical presentation, type of eclampsia, mode of delivery and its foetomaternal outcome.

\section{MATERIALS AND METHODS}

It was a retrospective descriptive study conducted in Christian Medical College and Hospital, Ludhiana over a period of 5 years. During this period, 70 patients presented in labour room with eclampsia. The data was collected from medical records of these patients. Socio-demographic 
parameters, clinical presentation, type of eclampsia, mode of delivery, maternal and perinatal morbidity and mortality were noted. The sample size estimation (70) was done at convenience. The following protocol was seen in most of the patients-

1. Supportive therapy in the form of IV-line, mouth gag, suction, catheterisation and oxygen inhalation were given.

2. All the cases were put on Pritchard regimen (Total $14 \mathrm{gms}$ of magnesium sulphate with $4 \mathrm{gm}$ IV bolus dose and $5 \mathrm{gm}$ IM in each buttock followed by $5 \mathrm{gm}$ IM in alternate buttock 4 hourly).

3. After stabilisation of patient, obstetrical management was carried out.

\section{RESULTS}

The number of deliveries during this period in our institute was 6930 and 70 patients presented with eclampsia, so the incidence of eclampsia in this study was $1.01 \%$. Highest incidence of $58.6 \%$ (41) was seen in the age group of $19-24$ years and in primigravidae $43(61 \%)$. Most of the patients belonged to urban areas $55(79 \%)$, were illiterate $\left(<8^{\text {th }}\right.$ standard) 46 (66\%) and had irregular ANC check-ups. It was seen that $62(88.5 \%)$ patients were totally unbooked, 6 (8.5\%) were booked outside and 2 (2.8\%) were booked with us (Table 1). Antepartum eclampsia was found to be most common with $42(60 \%)$ presenting with it, which was followed by intrapartum eclampsia 24 (34\%), whereas only 4 (6\%) had postpartum eclampsia. Previous h/o antenatal high BP record was found in only $30(43 \%)$ patients. Most common prodromal symptom was headache 38 (54\%) followed by blurring of vision 16 (23\%). Other symptoms included dizziness 3 (4\%) and flashing of light (Table 2). Before presentation $60 \%$ patients had 2 - 4 episodes of seizures, blood pressure range was from 130/90 $\mathrm{mmHg}$ $220 / 110 \mathrm{mmHg}$. Injection labetalol was given to $61(87 \%)$ patients and oral labetalol was given to $9(13 \%)$ patients. All the patients received injection Magnesium sulphate (14 gms), out of which $5(7 \%)$ patients had received treatment outside. It was noted that $48(68.6 \%)$ patients presented to us at $<37$ weeks of gestation, while $22(31.4 \%)$ were at $>37$ weeks of gestation. High incidence was found in between $32-36$ weeks of gestation. In investigations $47(67 \%)$ had normal complete blood count, 61 (87.15\%) had raised liver function test, raised LDH in 64 (91.42\%), urine albumin 4+ was found in $14(20 \%)$ followed by $13(19 \%)$ who had $2+$. On fundoscopy $5(7.14 \%)$ were found to have hypertensive retinopathy. Blood transfusion was required in 18 (26\%) patients. Out of total patients presented with eclampsia- 23 (33\%) had normal vaginal delivery, 13 (18.6\%) had instrumental delivery, while 34 (48.6\%) had LSCS. Out of 36 vaginal deliveries 16 (22.8\%) were induced, while 20 $(18.8 \%)$ were in spontaneous labour and were augmented (Table 3). Maternal complications included HELLP syndrome $4(5.7 \%)$, postpartum haemorrhage in $2(2.85 \%)$, pulmonary oedema in $2(2.85 \%)$ and DIC in $1(1.42 \%)$. Acute renal failure disseminated intravascular coagulation and multiple organ dysfunction syndrome was the cause of $4(5.7 \%)$ maternal deaths (Table 2). In our study preterm deliveries occurred in $48(68.6 \%)$ patients. Neonatal outcome included live births in 57 (81.42\%), fresh still births in 8 (11.42\%) and $5(7.14 \%)$ already had intrauterine deaths. Out of these all newborns who had severe birth asphyxia were $5(8.8 \%)$, moderate birth asphyxia $9(15.8 \%)$, respiratory failure 13 (22.8\%), hypoxaemic-ischaemic encephalopathy 7 (12.3\%), hyaline membrane disease $6(10.5 \%)$, sepsis $5(8.8 \%)$, shock $5(8.8 \%)$, apnoea of prematurity $3(5.2 \%)$, while $4(7.01 \%)$ had meconium aspiration syndrome (Table 4).

\begin{tabular}{|c|c|c|}
\hline Age Group (Years) & No. of Patients (N= 70) & $\mathbf{( \% )}$ \\
\hline$<19$ & 1 & $1 \%$ \\
\hline $19-24$ & 41 & $59 \%$ \\
\hline $25-29$ & 18 & $26 \%$ \\
\hline $30-34$ & 6 & $9 \%$ \\
\hline$>35$ & 4 & $6 \%$ \\
\hline Education & & \\
\hline Educated & 24 & $34 \%$ \\
\hline (VIIIth standard and above) & 46 & $66 \%$ \\
\hline Illiterate & & \\
\hline Residence & 55 & $79 \%$ \\
\hline Urban & 15 & $21 \%$ \\
\hline Rural & & \\
\hline Gravida & 43 & $61 \%$ \\
\hline Primigravida & 27 & $39 \%$ \\
\hline Multigravida & 2 & \\
\hline Antenatal Booking & 6 & $3 \%$ \\
\hline CMCH Booked & 62 & $88.6 \%$ \\
\hline Booked outside & & \\
\hline Unbooked & Table 1. Demographic Features \\
\hline \multicolumn{2}{|c|}{} \\
\hline \multicolumn{2}{|c|}{} \\
\hline
\end{tabular}

\begin{tabular}{|c|c|c|}
\hline Prodromal Symptoms & $\begin{array}{c}\text { No. of Patients } \\
(\mathbf{N = 7 0 )}\end{array}$ & $\mathbf{\%}$ \\
\hline Blurring of vision & 16 & $23 \%$ \\
\hline Flashing of light & 0 & $0 \%$ \\
\hline Headache & 38 & $54 \%$ \\
\hline Dizziness & 3 & $4 \%$ \\
\hline Types of Eclampsia & & \\
\hline Antepartum & 42 & $60 \%$ \\
\hline Intrapartum & 24 & $34 \%$ \\
\hline Postpartum & 4 & $5.7 \%$ \\
\hline Maternal Complications & & \\
\hline HELLP syndrome & 4 & $5.7 \%$ \\
\hline Acute renal failure & 1 & $1.4 \%$ \\
\hline Abruptio placentae & 0 & 0 \\
\hline Postpartum haemmorhage & 2 & $2.8 \%$ \\
\hline Pulmonary oedema & 2 & $2.8 \%$ \\
\hline Maternal death & 4 & $5.7 \%$ \\
\hline DIC & 1 & $1.4 \%$ \\
\hline
\end{tabular}

Table 2. Prodromal Symptoms, Types of Eclampsia and Maternal Complications of Eclampsia

\begin{tabular}{|c|c|c|}
\hline Mode of Delivery & Number $(\mathbf{n = 7 0 )}$ & $\mathbf{\%}$ \\
\hline Vaginal & $\mathbf{2 3}$ & 33 \\
\hline Spontaneous & 13 & 19 \\
\hline Induced & 10 & 14 \\
\hline Instrumental & $\mathbf{1 3}$ & 19 \\
\hline Spontaneous & 7 & 10 \\
\hline Induced & 6 & 8.6 \\
\hline LSCS & $\mathbf{3 4}$ & 49 \\
\hline Meconium stained amniotic fluid & 6 & 8.6 \\
\hline Non-progression of labour & 10 & 14 \\
\hline Previous LSCS & 8 & 11 \\
\hline $\begin{array}{c}\text { Eclampsia with unfavourable } \\
\text { Bishop's score }\end{array}$ & 10 & \multirow{2}{*}{14} \\
\hline
\end{tabular}




\begin{tabular}{|c|c|c|}
\hline \multicolumn{3}{|c|}{ Table 3. Mode of Delivery } \\
\hline Foetal Outcome & \begin{tabular}{|c|} 
Number of \\
Babies $(n=65)$
\end{tabular} & (\%) \\
\hline Severe birth asphyxia & 5 & $7.7 \%$ \\
\hline Moderate birth asphyxia & 9 & $13.8 \%$ \\
\hline Apnoea of prematurity & 3 & $4.6 \%$ \\
\hline $\begin{array}{l}\text { Hypoxic-ischaemic } \\
\text { encephalopathy }\end{array}$ & 7 & $10.8 \%$ \\
\hline Sepsis & 5 & $7.7 \%$ \\
\hline Respiratory failure & 13 & $20 \%$ \\
\hline Meconium aspiration syndrome & 4 & $6.2 \%$ \\
\hline Shock & 5 & $7.7 \%$ \\
\hline Hyaline membrane disease & 6 & $9.2 \%$ \\
\hline Fresh stillborn & 8 & $11.8 \%$ \\
\hline Already IUD & 5 & $7.7 \%$ \\
\hline
\end{tabular}

\section{DISCUSSION}

Maternal mortality is unacceptably high in developing countries including India. Death of the mother has severe impact on the family, community and the nation. The young surviving children left motherless are unable to cope up with daily living and are at increased risk of death increasing perinatal and neonatal mortality. Life threatening conditions like eclampsia are preventable, which indicates that more efforts and Government resources should be utilised in these conditions. Reduction of maternal mortality is the objective of MDGs, especially in low income countries, where one die of pregnancy related complications. 5

The incidence of eclampsia in our study was $1.01 \%$ which was comparable to that described by Rajashri et al (1.82\%), a study conducted in a tertiary hospital in Bijapur. ${ }^{6}$ In India, reported incidence of eclampsia varies from 0.179 to $3.7 \%$ according to PN Nobis study. ${ }^{7}$ Highest incidence of eclampsia was found between 19 - 24 years in $58.6 \%$ (41) of the patients showing that this is a disease of young women. A study conducted at GG Hospital, Jamnagar, also highlights the same thing that young patients were at more risk of having eclampsia. In their study, 63 patients of eclampsia out of 70 $(90 \%)$ were $<24$ years. $^{8}$ Other studies also supported this. ${ }^{9}$ Our study depicts that $55(79 \%)$ patients were from urban area, 46 (66\%) were illiterate, 62 (88.5\%) were unbooked of low socio-economic status and with irregular ANC check-up which is comparable to other studies.7,9,10,11 This shows that in spite of available health care services in urban areas still due to illiteracy irregular ANC check-ups, eclampsia persists to be a problem in India thus increasing maternal mortality. Majority of the cases $43(61 \%)$ were primigravida as discussed by other studies. ${ }^{6-9,10-12}$ This brings the sad fact in front that eclampsia is killing women at prime of their life when she was about to start her family. Highest number of patients $40(57.14 \%)$ in our study were found between 32-36 weeks of gestation, which is comparable to other studies like in criteria-based audit on management of eclampsia patients at a tertiary hospital in Dar, which showed $67 \%$ patient who had eclampsia were primiparous and $46 \%$ were $<37$ weeks. ${ }^{12}$ Few studies showed more patients above 37 weeks of gestation.9,11 Most common prodromal symptom was headache 38 (54\%) followed by blurring of vision 16 (23\%), which is comparable to other studies. ${ }^{4}$ In this study at the time of presentation most of the patients 42 (60\%) had 2-4 episodes of seizures before presentation. Blood pressure range was from 130/90 $\mathrm{mmHg}-220 / 110 \mathrm{mmHg}$, for which anti-hypertensives were given. Injection labetalol was given to $61(87 \%)$ and oral labetalol was given to $9(13 \%)$ patients who were fully conscious. Injection magnesium sulphate was given to all the patients. $5(7 \%)$ patients had received treatment outside and similar regimen was followed in other studies.7,9,13 Eclampsia is a well-recognised complication of hypertensive disorders of pregnancy. If we teach at primary health centre the advantage of checking BP on each visit and taking care of the prodromal symptoms, patient can be referred at an early stage and chances of eclampsia can be decreased in future. Relevant investigations revealed normal CBC in 47 (67\%), raised liver function test in 61 (87.15\%), raised LDH was found in 64 (91.42\%). Proteinuria was checked showing $14(20 \%)$ had albumin $4+$ followed by 13 (19\%) had 2+ which is comparable to other studies.9,11 On fundoscopy, $5(7.14 \%)$ were found to have hypertensive retinopathy. Blood transfusion was done in 18 (26\%) patients.

The definitive treatment of eclampsia is delivery, irrespective of gestational age. Therefore, the patient must be delivered within 24 hours in case of severe preeclampsia and within 12 hours in a patient with eclampsia. ${ }^{14}$ Out of total patients presented with eclampsia 23 (33\%) had normal vaginal delivery, instrumental delivery was in 13 (18.6\%), while 34 (48.6\%) had LSCS. Out of 36 vaginal deliveries 16 (22.8\%) were induced, while 20 (18.8\%) were in spontaneous labour and were augmented. LSCS was the commonest mode of delivery in other studies.9,15,16 Our study highlights that indication of LSCS should not be eclampsia alone, rather decision of LSCS should be made on the basis of control of blood pressure by anti-hypertensives, period of gestation at presentation, control of convulsions, general condition of patient and Bishop's score. If blood pressure is under control with no more convulsions, gestation $>34$ weeks and good Bishop's score, then pregnancy can be terminated by induction. In India maternal mortality due to eclampsia is very high with range between 2.2 to $23 \% .{ }^{17}$ Maternal complications included HELLP syndrome in 4 (5.7\%) patients followed by PPH in $2(2.85 \%)$, pulmonary oedema in $2(2.85 \%)$ and disseminated intravascular coagulation in $1(1.42 \%)$. Acute renal failure disseminated intravascular coagulation and multiple organ dysfunction syndrome was the cause of $4(5.7 \%)$ maternal deaths, which is comparable to a study 9 by Tuffnel DJ. More than one complication was seen in these patients. In our study, preterm deliveries occurred in $48(68.6 \%)$ patients. The percentage of live births and still birth in our study was $81.42 \%$ and $11.42 \%$ respectively. As many as 5 patients already had intrauterine deaths. As the established treatment of eclampsia is delivery whatever is the gestation. Preterm deliveries were common and so the premature babies and all the associated complications. Further intrauterine growth retardation in these babies play a significant role in causing other complications.18,19 These babies are usually asphyxiated because of seizures and adding the element of prematurity and IUGR results in early neonatal deaths. ${ }^{9}$

\section{CONCLUSION}

Eclampsia is a preventable complication of pregnancy, but still remains the major cause of maternal mortality in India. There is a need to educate and encourage the general public to opt for prompt antenatal care and hospital delivery. Mass 
awareness is required for importance of early antenatal booking, regular antenatal check-ups, proper heath education and nutrition, and ensuring early detection of preeclampsia in peripheral hospitals. Preliminary treatment at peripheral health centre with timely referral to tertiary care hospital is the key to curb this problem.

\section{REFERENCES}

[1] Andersgaard AB, Herbst A, Johansen $M$, et al. Eclampsia in Scandinavia: incidence, substandard care and potentially preventable cases. Acta Obstet Gynecol Scand 2006;85(8):929-36.

[2] Konar J. Hypertensive disorders in pregnancy. In: Dutta DC, edr. Textbook of Obstetrics. $7^{\text {th }}$ edn. Kolkata, India: New Central Book Agency 2011: p. 219-40.

[3] Manyemba J. Magnesium sulphate for eclampsia: putting the evidence into clinical practice. Cent Afr J Med 2000;46(6):166-9.

[4] Duley L. Maternal mortality associated with hypertensive disorder of pregnancy in Africa, Asia, Latin America and Caribbean. Br J Obstet Gynecol 1992;99(7):547-53.

[5] Kidanto HL, Mogren I, Massawe SN, et al. Criteriabased audit on management of eclampsia patients at a tertiary hospital in Dar es Salaam, Tanzania. BMC Pregnancy and Childbirth 2009;9:13.

[6] World Health Organisation and Unicef. Countdown to 2015 Decade report (2000-2010): taking stock of maternal, newborn and child survival. Geneva: WHO and UNICEF, 2010. (http//www.childinfo.org/files/countdown Report 2000-2010.pdf) Accessed 17 August 2011.

[7] Das R, Biwas S, Mukherjee A. Maternal mortality at a teaching hospital of rural India: a retrospective study. International Journal of Biomedical and Advance Research 2014;5(2):114-7.

[8] Gurina NA, Vangen S, Forsen L, et al. Maternal mortality in St. Petersburg, Russian Federation. Bull World Health Organisation 2006;84:283-9.
[9] Yaliwal RG, Jaju PB, Vanishree M. Eclampsia and perinatal outcome: a retrospective study in a teaching hospital. J of Clinical and Diagnostic Research 2011;5(5):1056-9.

[10] Nobis PN, Hajong A. Eclampsia in India through the decades. J Obstet Gynaecol India 2016;66(Suppl 1):172-6.

[11] Trivedi K, Patel E, Patel N, et al. The maternal outcome in antepartum eclampsia in tertiary care hospital. Asia Pacific Journal of Research 2014;1(17):10-15.

[12] Raji C, Poovathi M, Nithya D, et al. Prospective study of fetomaternal outcome in eclampsia in a tertiary care hospital. Int J Reprod Contracept Obstet Gynecol 2016;5(12):4329-34.

[13] Prabhakar G, Shinde MA, Jadhav CA. Clinical study of eclampsia patients at Dr. V M. Government medical college Solapur, India. IOSR Journal of Dental and Medical Sciences 2014;13(7):10-6.

[14] Kumari S, Bhavani, Himabindu P, et al. Clinical study of eclampsia and outcome in a tertiary care centre. IOSR Journal of Dental and Medical Sciences 2015;14(2)106-9.

[15] Singh BM, Mishra R. Hypertensive disorders. In: Mishra R, edr. Ian Donald's Practical obstetric problem. $7^{\text {th }}$ edn. New Delhi: BI Publications Pvt Ltd., 2014: p. 142-75.

[16] Choudhary P. Eclampsia: a hospital based retrospective study. Kathmandu University Medical Journal (KUMJ) 2003;1(4):237-41.

[17] Manjusha S, Vandna N, Goutham R, et al. Eclampsia: a retrospective study in a tertiary care centre. Indian Journal of Pharmacy Practice 2013;6(1):69-73.

[18] Pal A, Bhattacharjee R, Bannerjee Ch, et al. Maternal mortality over a decade in a referral Medical College Hospital, West Bengal. Indian J Perinatol Reprod Biol 2001;04:10-3.

[19] Lee W, O'Connell CM, Baskett TF. Maternal and perinatal outcome of eclampsia: Nova Scotia, (19812000). J Obstet Gynecol 2004;26(2):119-23. 